\title{
PERANCANGAN RANGKA PADA ALAT PENYIMPANAN BARANG
}

\author{
Muhammad Yunus \\ Program Studi Teknik Mesin, Fakultas Teknik, Universitas Muhammadiyah Riau \\ Jalan Tuanku Tambusai Ujung, Kecamatan Tampan, Kelurahan Delima, Kota Pekanbaru, Riau \\ 28291 \\ E-mail: muhammadnoe8@gmail.com
}

\begin{abstract}
Currently, the development of universities in Indonesia is very fast both in quality and infrastructure. To help increase the security of important items being carried, goods storage devices are needed. Storage tools are designed to help put things in so that they are comfortable and not afraid of loss. The design of the frame on the goods storage device by calculating the strength of the welded joint on the frame. The storage frame for the goods is designed in three levels with a size of $162 \mathrm{~cm}$ (length), $56 \mathrm{~cm}$ (width), and $168 \mathrm{~cm}$ (height). By using NDT analysis and the frame material used is rectangular perforated iron with a size of $30 \times 30 \times 1 \mathrm{~mm}$. All loads on the frame including the cover plate of the frame are assumed to be $100 \mathrm{~kg}$. Then the theoretical calculation is obtained the weld strength is $0,047 \mathrm{~N} / \mathrm{mm}^{2}$. The calculation result is still below the safety figure.
\end{abstract}

Keywords: Frame, Size Of Frame, Strength Of Frame Connection, Welding, The Strength OF The Welding joint

\begin{abstract}
Abstrak
Saat ini perkembangan Universitas di Indonesia sangat pesat baik secara kualitas maupun infrastuktur. Untuk membantu meningkatkan keamanan barang penting yang dibawa maka dibutuhkan alat penyimpanan barang. Alat penyimpanan barang dirancang untuk membantu meletakan barang sehingga membuat kenyamanan dan tidak takut terja dikehilangan. Perancangan rangka pada alat penyimpanan barang dengan menghitung kekuatan sambungan las pada rangka. Rangka penyimpanan barang tersebut didesain tiga tingkat dengan ukuran $162 \mathrm{~cm}$ (panjang), $56 \mathrm{~cm}$ (lebar), dan $168 \mathrm{~cm}$ (tinggi). Dengan menggunakan analisa NDT dan material rangka yang digunakan adalah besi segiempat berlubang dengan ukuran $30 \times 30 \times 1 \mathrm{~mm}$. Semua beban pada rangka termasuk plat penutup rangka diasumsikan ialah $100 \mathrm{~kg}$. Maka perhitungan yang dilakukan secara teoritis didapatkan kekuatan lasnnya $0,047 \mathrm{~N} / \mathrm{mm}^{2} .$. Hasil perhitungan tersebut masih dibawah angka keamanan..
\end{abstract}

Kata kunci: Rangka, Ukuran Rangka, Kekuatan Sambungan Rangka, Pengelasan, Kekuatan Sambungan Pengelasan

\section{Pendahuluan}

Universitas Muhammadiyah Riau merupakan suatu lembaga pendidikan yang perkembangannya cukup pesat baik secara kualitas maupun infrastruktur. Dengan perkembangannya yang cukup pesat tentunya Universitas Muhammadiyah Riau memberi kenyamanan dan dukungan fasilitas didalam kampus untuk mendorong terciptanya lingkungan kampus yang kondusif, salah satu fasilitas yang ada di Universitas Muhammadiyah Riau adalah Masjid Baitul Hikmah. Pada saat adzan berkumandang mahasiswa dan dosen melaksanakan sholat berjamaah di Masjid Baitul Hikmah. Barang atau tas yang dibawa oleh mahasiswa dan dosen selalu terbengkalai dan tidak ada yang menjaga, sehingga membuat ketidaknyamanan dalam mengerjakan ibadah di Masjid Baitul Hikmah. Untuk memberikan keamanan barang bawaan, maka dibutuhkan lemari penitipan barang.

Dengan memanfaatkan kemajuan teknologi saat ini, box atau kotak penyimpanan barang, akan dibuat bagian lock kotak penyimpanan barang terbuka secara otomatis dengan system Radio Frequency Identification (RFID) menggunakan kartu. Penyimpanan barang 
otomatis akan dibuat menggunakan Programable Logic Controller (PLC) dan tuas pengunci pintu untuk membuka pintu kotak penyimpanan barang. Dengan adanya kotak penyimpanan barang otomatis ini semua akan bisa ikut melaksanakan sholat berjamaah dengan tenang.

Dalam pembuatan alat penyimpanan barang tersebut memerlukan pembuatan rangka. Dalam pembuatan rangka (frame) harus melakukan beberapa penelitian, untuk menentukan bahan, menentukan ukuran rangka (frame), juga mengukur kekuatan rangka yang akan dibuat. Oleh sebab itu, maka dibutuhkan suatu perancangan, yaitu :

1. Bagaimana bentuk rangka untuk penyimpan barang tersebut?

2. Bagaimana proses pembuatan rangka penyimpanan barang?

3. Bagaimana hasil perhitungan kekuatan rangka dari hasil pengujian teoristis?

4. Bagaimana hasil perhitungan kekuatan sambungan las secara teoristis ?

Berdasarkan dengan rumusan masalah, maka tujuan dari perancangan rangka pada alat penyimpanan barang adalah untuk meningkatkan fasilitas kampus dan memberikan keamanan barang yang dibawa dengan melakukan pembuatan rangka dengan baik. menghitung dan mengetahui hasil pengujian kekuatan rangka dan sambungan las secara teoristis.

\section{Metodologi}

Perancangan rangka merupakan salah satu hal yang penting dalam proses perancangan secara keseluruhan, karena rangka merupakan landasan utama dalam menaruh seluruh komponen mesin. Pembuatan rangka pada alat penyimpanan barang dirancang sesuai dengan ukuran barang yang akan diletakkan pada lemari penyimpanan barang tersebut. pembuatan rangka penyimpanan barang didesain untuk mengejar efisiensi tempat untuk komponen komponen seperti tas, laptop dan lain-lainnya.

Dalam pembuatan rangka penyimpanan barang ini ada beberapa faktor yang menjadi pertimbangan, yaitu: rangka dapat menopang semua beban komponen-komponen serta muatan didalamnya, rangka tidak cepat terjadi kerusakan, ukuran rangka perkotak seukuran tas yang di asumsikan $50 \mathrm{~cm}$. Kemudian setelah melakukan desain dari rangka tersebut barulah dilakukan pemilihan bahan yang akan digunakan. Pemilihan bahan untuk membuat rangka penyimpanan barang ini yaitu menggunakan jenis bahan besi (iron), karena jenis dan ukuran bahan ini sesuai dengan desain yang akan dibuat, bahan ringan serta tidak menimbukan tonjolan pada saat komponen dipasangkan baut pengikat.

Pengukuran bahan dilakukan sebelum memotong besi sesuai bentuk yang telah di tentukan. Adapun beberapa alat yang digunakan pada proses pengukuran dan pemotongan, yaitu :
a. Gerinda Potong
b. Penggaris
c. Kapur
d. Ear plug
e. Sarung Tangan
f. Kaca mata
g. Masker

Selanjutnya proses pengelasan bahan menggunakan mesin las listrik dengan elektroda yang digunakan berukuran 2,6mm x 350mm. Alasan pemilihan penyambungan dengan las listrik yaitu untuk mendapatkan sambungan yang kuat, karena rangka penyimpanan barang ini harus mampu menerima beban yang cukup berat. Adapun alat yang diperlukan dalam pengelasan, yaitu:
a. Kawat las
b. Mesin las
c. Masker
d. Kaca mata las
e. Sarung tangan
f. Palu
g. Penggaris

Untuk memastikan bahwa rangka yang dirancang aman dan layak digunakan, maka diperlukan suatu rencana pengujian yang bertujuan untuk mengetahui layak atau tidaknya hasil dari pembuatan rangka tersebut. Adapun pengujiannnya sebagai berikut :

1. Pengujian kelayakan alat, Pengujian dilakukan dengan cara di uji secara teoritis berdasarkan data yang sudah ada, dalam menguji kekuatan bahan ini mengguakan teori uji ketahanan bengkok.

2. Pengujian kelayakan sambungan las, Penyambungan bahan untuk pembuatan rangka ini menggunakan sambungan las listrik, karena sambungannya lebih kuat dari pada sambungan lainnya. Jenis sambungan las yang dipakai yaitu jenis sambungan las ujung.

3. Pengujian hasil pengelasan menggunakan petrant liquid, Pengujian ini dilakukan dengan cara menyemprotkan cairan penetran ke 
bagian yang sudah di las agar mengetahui kualitas pengelasan.

\section{Hasil Dan Pembahasan}

Perancangan rangka untuk penyimpanan barang dengan mengunakan bahan besi segiempat berlubang $30 \mathrm{~mm}$ x $30 \mathrm{~mm}$ dengan tebal $1 \mathrm{~mm}$. Untuk melakukan proses desain menggunakan Software Autocad sesuai dengan perhitungan ukuran dan model yang sudah ditentukan seperti gambar dibawah ini :

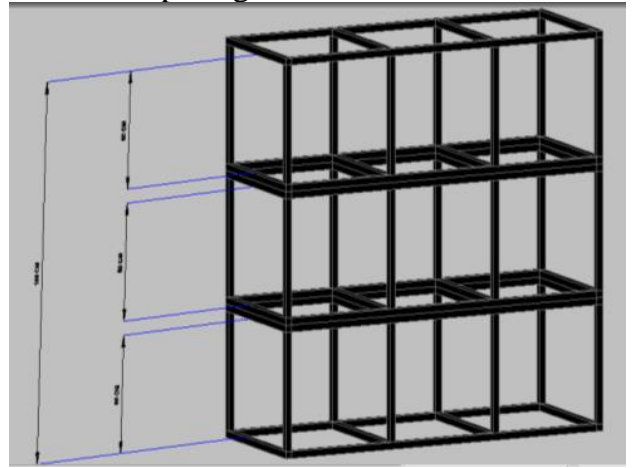

Gambar 1. Desain Rancangan Pembuatan angka

Rencana rangka yang akan dibuat ada beberapa bagian yaitu rangka bagian atas, rangka bagian tengah dan rangka bagian bawah yang memiliki 3 ruang yang berbentuk kotak dengan masing-masing memiliki ruang berukuran $50 \mathrm{~cm}$ dan setiap bagian-bagian rangka kotak tersebut akan disatukan menggunakan baut sebagai pengikat. Adapaun proses yang dilakukan dalam pembuatan rangka ini yaitu :

1. Proses pemotongan bahan

Proses pemotongan bahan dilakukan menggunakan gerinda potong dan mesin potong besi. Besi dipotong menggunakan gerinda tangan setelah sebelumnya sudah dilakukan pengukuran sesuai desain. Untuk mendapatkan hasil yang baik, maka pengerjaan dilakukan melalui beberapa tahap, yaitu :

a. Mengukur besi yang akan di potong dengan memberikan garis

b. Merapikan hasil pemotongan

c. Mempersiapkan besi yang sudah dipotong disusun sesuai rancangan

d. Membersihkan permukaan yang akan di las

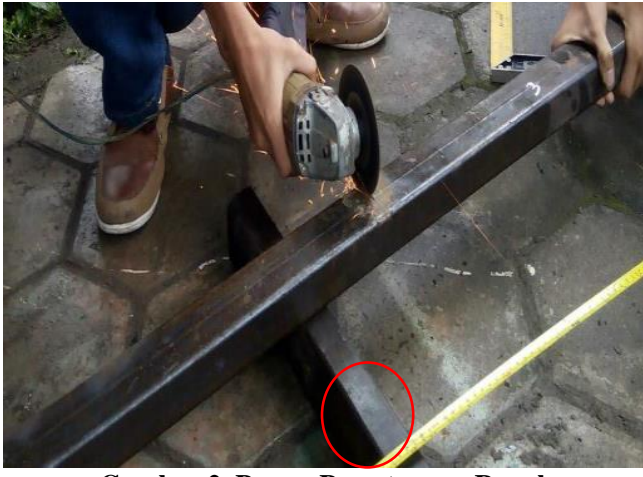

Gambar 2. Proses Pemotongan Rangka

2. Proses pengelasan

Proses pengelasan dilakukan dengan beberapa tahap bagian rangka yaitu meliputi pengelasan rangka kotak bagian atas, rangka bagian tengah, rangka bagian bawah. Metode pengelasanya menggunakan las listrik, karena pengelasan ini cukup kuat untuk pengelasan rangka. Setelah semua bagian-bagian rangka di las, tahap selanjutnya adalah proses perapian bagian-bagian pengelasan yang kurang rapi dengan menggunakan gerinda penghalus dan sikat baja.

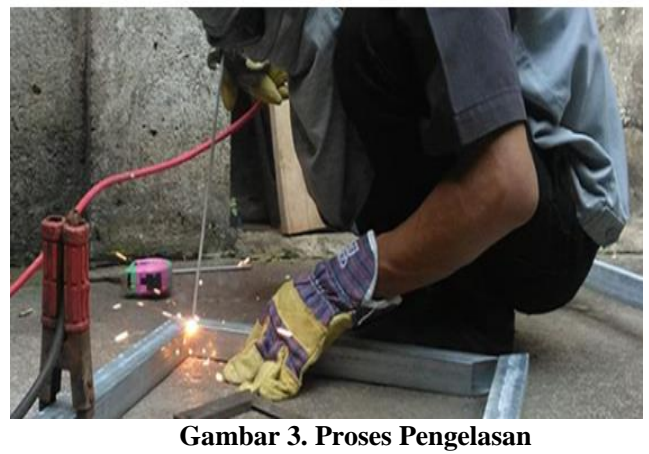

\section{Proses finishing}

Dalam proses finishing ada beberapa tahap pengerjaan, yaitu tahap penghalusan hasil pengelasan, pendempulan rangka, pengamplasan dan pengecatan rangka. Penghalusan hasil pengelasan bertujuan untuk membersihkan permukaan lasan dari kerak yang dihasilkan saat proses pengelasan. Proses ini dilakukan menggunakan palu kerak, gerinda penghalus dan sikat baja. Proses pendempulan dan pengamplasan rangka ini bertujuan untuk menutup lubang-lubang dan juga menghilangkan karat pada hasil pengelasan. Selanjutnya proses pengecatan ini bertujuan untuk melindungi rangka dari karat supaya rangka dapat bertahan lama. Proses pengecatan ini menggunakan cat berwarna abu-abu dan metode pengecatanya menggunakan spray.

4. Proses analisa dan pengujian 
Ada beberapa tahapan pengujian dan menganalisa bentuk rangka tersebut, yaitu :

1. Pengujian pengelasan menggunakan petrant liquid, Analisa ini dilakukan dengan cara menyemprotkan cairan penetran ke bagian yang sudah di las agar mengetahui kualitas pengelasan.

2. Pengujian kelayakan rangka,

Pengujian ini dilakukan dengan cara di uji secara teoritis berdasarkan data yang sudah ada,untuk mengetahui kekuatan bahan yang digunakan. Dalam menguji kekuatan bahan ini mengguakan teori uji ketahanan bengkok, dan setelah dihitung secara teoritis bahan yang digunakan layak untuk pembuatan rangka penyimpanan barang tersebut yaitu menghitung tegangan pada rangka, Tegangan yang terjadi pada rangka adalah tegangan bengkok. Rumus mencari tegangan bengkok:

$$
\begin{gathered}
\sigma_{b}=\frac{M b}{W b} \\
M_{b}=\frac{f . I}{2}
\end{gathered}
$$

f: beban komponen-komponen yang di terima oleh rangka sekitar ( $\mathrm{f}=100 \mathrm{~kg}$ ), karena beban rangka ditahan oleh 60 potong rangka maka $f=100: 60=1,6 \mathrm{~kg}, 1$ panjang rangka $(1=$ $1620 \mathrm{~mm}$

$$
\begin{aligned}
M_{b} & =\frac{f . I}{2} \\
M_{b} & =\frac{1,6 \cdot 1620}{2} \\
& =1296 \mathrm{~kg} . \mathrm{mm}
\end{aligned}
$$

Jadi, momen bengkok yang terjadi pada rangka yaitu $1296 \mathrm{~kg} . \mathrm{mm}$. momen bengkok ini sebagai dasar untuk menentukan tegangan bengkok yang terjadi pada rangka.

Setelah momen bengkok maksimal sudah diketahui kemudian mencari momen tahanan bengkok untuk bahan yang digunakan untuk membuat rangka. Bahan yang digunakan untuk membuat rangka yaitu baja karbon dengan ukuran 30 x $30 \times 1 \mathrm{~mm}$. Berikut adalah penghitungan untuk mencari momen tahanan bengkok untu penampang segiempat berlubang:

$$
\begin{aligned}
\mathrm{Wb} & =\frac{\frac{1}{6}\left(\mathrm{~b} \cdot \mathrm{h}^{3}-\mathrm{b} 1 \cdot \mathrm{h} 1^{3}\right)}{h} \\
\mathrm{~Wb} & =\frac{\frac{1}{6}\left(30.30^{3}-28.28^{3}\right)}{30} \\
& =1085,2 \mathrm{~mm}^{3}
\end{aligned}
$$

Setelah mencari momen tahanan bengkok kemudian menghitung tegangan bengkok yang terjadi pada rangka

$$
\begin{gathered}
\sigma_{b}=\frac{M b}{W b} \\
\sigma_{b}=\frac{1296}{1085,2}
\end{gathered}
$$

$$
\begin{aligned}
& =1,19 \mathrm{~kg} / \mathrm{mm}^{2} \\
& =11,9 \mathrm{~N} / \mathrm{mm}^{2}
\end{aligned}
$$

Jika $1 \mathrm{~kg} / \mathrm{mm} 2=10 \mathrm{~N} / \mathrm{mm}^{2}$, maka $\sigma_{b}=$ $1,19 \mathrm{~kg} / \mathrm{mm}^{2}$ x $10=11,9 \mathrm{~N} / \mathrm{mm}^{2}$. Kemudian bahan yang digunakan untuk membuat rangka lemari yaitu baja ST 37, dengan $\sigma_{b}=360$ $\mathrm{N} / \mathrm{mm}^{2}$, faktor keamanan (sf) yang dipakai untuk menahan beban yaitu $5-10 \mathrm{~N} / \mathrm{mm}^{2}$.

Tegangan bengkok yang di izinkan

$$
\sigma_{b} \text { ijin }=\frac{\sigma_{b}}{s f}=\frac{360}{10}=36 \mathrm{~N} / \mathrm{mm}^{2}
$$

Sehingga di dapat $\sigma_{b}<\sigma_{b}$ ijin (rangka aman untuk menopang beban komonen- komponen rangka).

3. Pengujian kelayakan sambungan las

Penyambungan bahan untuk pembuatan rangka ini menggunakan sambungan las busur listrik, karena sambungan ini lebih kuat daripada sambungan baut. Setelah proses penghitungan sambungan las ini dilakukan maka sambungan las tersebut bisa dikatakan layak.

Sambungan las yang digunakan yaitu jenis sambungan las ujung dengan ujung segiempat. Penghitungan las pada sambungan ini, beban yang diterima rangka adalah $100 \mathrm{~kg}$ didapat dari asumsi berat dari barang. Karena pengelasan pada sambungan antara rangka dengan rangka lainnya ada 48 titik pengelasan, maka beban keseluhan dibagi 48 yaitu $100: 48=2,08 \mathrm{~kg}$.

Mencari panjang las bersih,

Tebal las $=4 \mathrm{~mm}$

$$
\begin{aligned}
\mathrm{BD}=\mathrm{a}= & \frac{t}{\sqrt{2}} \\
& =\frac{4}{\sqrt{2}} \\
& =\frac{4}{1,414} \\
& =2,8288 \mathrm{~mm} \\
\text { Ibersih } & =\text { Ikotor }-2 . \mathrm{a} \\
& =100-4.2 .2,8288 \\
& =77,3 \mathrm{~mm}
\end{aligned}
$$

Mencari gaya $(\mathrm{F})$

$$
\begin{aligned}
\mathrm{F} & =\mathrm{m} \cdot \mathrm{g} \\
& =2,08 \cdot 10 \\
& =20,8 \mathrm{~N}
\end{aligned}
$$

Mencari tegangan geser pada penampang las:

$$
\begin{aligned}
t_{g} & =\frac{f}{\sqrt{2 \cdot t \cdot I}} \\
& =\frac{20,8}{\sqrt{(2) 4 \cdot 77,3}} \\
& =\frac{20,8}{437,27} \\
& =0,047 \mathrm{~N} / \mathrm{mm}^{2}
\end{aligned}
$$

Jadi, tegangan geser yang terjadi pada las yaitu $0,047 \mathrm{~N} / \mathrm{mm}^{2}$. Dari tegangan geser yang diijinkan untuk bahan jenis ST37 yang memiliki 
tegangan geser maksimal $185 \mathrm{~N} / \mathrm{mm}^{2}$, dengan angka keamanan (sf) untuk beban kejut yaitu $10 \mathrm{~N} / \mathrm{mm}^{2}$

$$
\begin{aligned}
t_{g} \text { ijin } & =\frac{t_{g}}{s f} \\
& =\frac{185}{10} \\
& =18,5 \mathrm{~N} / \mathrm{mm}^{2}
\end{aligned}
$$

Sehingga $t_{g}$ penampang las $<t_{g}$ ijin (kekuatan sambungan las antara rangka aman untuk menahan beban seluruh barang).

\section{Simpulan}

Berdasarkan hasil dari penelitian yang telah dilakukan maka dapat dilihat bahwa perancangan rangka dilakukan melalui tahap desain mengunakan Software Autocad. Rencana rangka yang dibuat ada beberapa bagian yaitu rangka bagian atas, rangka bagian tengah dan rangka bagian bawah yang memiliki 3 ruang yang berbentuk kotak dengan masing-masing ruang berukuran $50 \mathrm{~cm}$ dengan menggunakan bahan besi segiempat berlubang ukuran $30 \mathrm{~mm}$ x $30 \mathrm{~mm}$.

Selanjutnya pemotongan bahan sesuai dengan ukuran rangka, Kemudian pengelasan untuk menyatukan setiap rangka sesuai desain yang sudah di buat dan tahap terakhir pembersihan komponen yang sudah dilas dan pengecatan.

Dalam pengujian kekuatan bahan dilakukan secara teoritis dengan menghitung tegangan bengkok. Perhitungan tegangan bengkok maksimal ditinjau dari bahan untuk membuat rangka dan ukuran bahan yang digunakan sehingga di ketahui hasil perhitungan tegangan bengkok maksimal $1,19 \mathrm{~kg} / \mathrm{mm}^{2}$ angka tersebut masih di bawah tegangan yang di ijinkan dari bahan. Dari hasil perhitungan tersebut dapat dikatakan bahwa bahan tersebut aman untuk digunakan dalam pembuatan rangka kotak penyimpanan barang tersebut.

Penelitian ini hanya membahas perancangan rangka berdasarkan analisis kekuatan rangka dan kelayakan sambungan las. Masih banyak analisis rangka yang dapat dilakukan melalui Software Autocad ataupun melalui analisis lainnya yang lebih baik dan efektif untuk pengembangan penelitian selanjutnya.

\section{Daftar Pustaka}

[1] Harsono Wiryosumarto, Toshie Okumura. Teknologi Pengelasan Logam. Jakarta:Erlangga. 2008

[2] Yuspian Gunawan, Nanang Endriatno, dan Bayu Hari Anggara. Analisa pengaruh pengelasan listrik terhadap sifat mekanik baja karbon rendah dan baja karbon tinggi. Universitas Halu Oleo. Kendari. 2017

[3] Stolk, Kros. Elemen Konstruksi Bangunan Mesin. Jakarta: Erlangga. 1986

[4] Mulyadi, Fentje Abdul Rauf, dan Rudy Poeng. Aplikasi perangkat lunak untuk perencanaan pengelasan pada material baja. Teknik Mesin Universitas Sam Ratulangi. Manado. 2013

[5] Riswan Dwi Jatmiko. Modul Teori Pengelasan logam. Teknik Mesin Universitas Negeri Yogyakarta. 2008

[6] Rudi Siswanto. Teknologi Pengelasan. Teknik Mesin Lambung Mangkurat. Banjarmasin. 2018

[7] Bintoro, A. G. Dasar-dasar Pekerjaan Las. Yogyakarta: Penerbit Kanisius. 2000 Suparman. Mekanika Teknik II. Universitas Negeri Yogyakarta. 2009

[8] Soelarso. Modul Analisis Struktur I. Universitas Sultan Ageng Tirtayasa. 2011

[9] Sukaswanto. Kumpulan Modul Elemen Mesin. Yogyakarta : FT UNY. 2004

[10] Sukaswanto. Kumpulan Modul Statika dan Kekuatan Material. Yogyakarta: FT UNY. 2004

[11] Tata Sudira, Sinroku Saito. Pengetahuan Bahan Teknik. Jakarta: PT. Pradaya Paramita. 1999

[12] Khurni,R.S dan Gupta,J.K. Machine Design. New Delhi: Eurasia Publising House. 1982

[13] Akbar Sudrajat. Perancangan dan Pembuatan Rangka Mobil Barang 13. Universitas Negeri Yogyakarta. 2017 